\title{
Comparison of levonorgestrel-releasing intrauterine system, medroxyprogesterone and norethisterone for treatment of endometrial hyperplasia without atypia: a randomized clinical trial
}

\begin{abstract}
Objective: To assess the efficacy, acceptability and cost-effectiveness of the levonorgestrelreleasing intrauterine system (LNG-IUS) compared to oral Medroxyprogesterone (MPA) and Norethisterone (NETA) for treatment of endometrial hyperplasia (EH) without atypia in perimenopausal women.

Methods: This randomized clinical study included 150 perimenopausal women with endometrial hyperplasia $(\mathrm{EH})$ without atypia who were randomly assigned into three groups; 50 patients received $15 \mathrm{mg}$ Medroxyprogesterone acetate (MPA), 50 patients received 15 mg Norethisterone acetate (NETA) and 50 patients in whom levonorgestrel-releasing intrauterine system (LNG-IUS) was inserted. Endometrial sampling was repeated after 6 months of therapy. Primary outcome was regression of EH while secondary outcomes included side effects, patient acceptability and cost of treatment over six months.
\end{abstract}

Results: There was no significant difference between the three groups regarding regression of EH $(p<0.05)$. The LNG-IUS has the highest cost and acceptability $(\mathrm{p}<0.001)$. There was a significant higher women suffering from nausea in NETA group $(\mathrm{p}<0.05)$, acne in MPA $\operatorname{group}(\mathrm{P}<0.05)$ and vaginal discharge in $\mathrm{LNG}-\mathrm{IUS}$ group $(\mathrm{p}<0.05)$.

Conclusion: In low-income and developing countries where the LNG-IUS is non affordable or unavailable, the use of norethisterone seems a viable cost-effective therapy in patients with endometrial hyperplasia without atypia.

Keywords: Endometrial hyperplasia, Levonorgestrel-releasing intrauterine system, Medroxyprogesterone, Norethisterone, Perimenopausal bleeding
Volume 5 Issue 4 - 2016

\author{
Mohamed Rezk, Mohamed Kandil, Said \\ Saleh, Abdelhamid Shaheen \\ Department of Obstetrics and Gynecology, Menoufia University, \\ Egypt
}

Correspondence: Mohamed Rezk, Department of Obstetrics and Gynecology, Faculty of Medicine, Menoufia University, Menoufia, Egypt, Email m_rezk9207@yahoo.com

Received: July 27, 2016 | Published: November 04, 2016

\section{Introduction}

Endometrial hyperplasia (EH) is characterized by nonphysiological proliferation of endometrium that results in glands with irregular shapes and varying sizes. The World Health Organization (WHO) 1994 classification system is commonly used, in which the architectural disruption and cytological atypia are used to identify four types of $\mathrm{EH}$, including simple or complex hyperplasia with or without atypia. ${ }^{1-3}$ Surgical management of EH namely endometrial ablation and hysterectomy are highly effective,but are associated with perioperative and long-term complication risks. ${ }^{4,5}$ Progestin treatment in various forms have been used for treatment of $\mathrm{EH}$ with proven efficacy including oral medroxyprogesterone, oral norethisterone, oral lynestrenol or micronized progesterone in vaginal cream. ${ }^{6-10}$

The levonorgestrel-releasing intrauterine device (LNG-IUS) releasing $20 \mu \mathrm{g}$ levonorgestrel per 24 hours was developed for the beneficial effects of intrauterine and hormonal contraception and for the treatment of menorrhagia. ${ }^{10}$ The aim of our study was to assess the efficacy, acceptability and cost-effectiveness of the levonorgestrel-releasing intrauterine system (LNG-IUS) compared to oral Medroxyprogesterone (MPA) and Norethisterone (NETA) for treatment of endometrial hyperplasia $(\mathrm{EH})$ without atypia in perimenopausal women.

\section{Material and methods}

This single-centre balanced randomized parallel group study was performed at the Department of Obstetrics and Gynecology, Menoufia University Hospital, Menoufia, Egypt in the period between June 2012 and June 2016. The review board and the Ethics Committee of Menoufia Faculty of Medicine approved the study. The study protocol and its benefits and complications were explained to all participants, and all recruited patients completed and signed an informed consent form. Eligibility criteria included menstruating perimenopausal women above the age above 40 years presented with AUB with histologically confirmed endometrial hyperplasia without atypia, following clinical examination, transvaginal sonography and endometrial sampling by Pipelle. Women with associated lesions as uterine fibroid, cervical or vaginal pathology, bleeding tendency, hormonal contraception in the past three months, chronic medical diseases as diabetes mellitus, hypertension, chronic liver disease, any contraindication to progestin therapy and postmenopausal women were excluded from the study.

Based on the $80-90 \%$ regression rate of endometrial hyperplasia under progestin therapy from the literature. Accordingly, at alpha = 0.05 and a study power of $80 \%$ a total sample size of 135 participants (45 participants in each group) was required after adding a percentage of $10 \%$ for possible drop out cases during the study. A total of 162 perimenopausal women (98 with simple EH and 64 with complex EH) were enrolled and equally allocated into three groups via computer generated simple random tables according to the allocation ratio 1:1:1. Twelve patients were dropped out from the study (stopped treatment and lost follow up), accordingly 150 patients completed the study. 
i. Group 1(MPA group): included 50 patients (32 with simple EH and 18 with complex EH) who received $15 \mathrm{mg}$ of medroxyprogesterone acetate in the form of $5 \mathrm{mg}$ tablet three times per day orally for 14 days per month (Provera $5 \mathrm{mg}$ tablets, Pfizer, USA) for 6 months.

ii. Group 2 (NETA group): included 50 patients (31 with simple EH and 19 with complex $\mathrm{EH}$ ) who received $15 \mathrm{mg}$ of norethisterone acetate in the form of $5 \mathrm{mg}$ tablet three times per day orally for 14 days per month (Cidolut nor $5 \mathrm{mg}$ tablets, CID pharmaceuticals, Cairo, Egypt) for 6 months.

iii. Group 3 (LNG-IUS group): included 50 patients (33 with simple EH and 17 with complex EH) to whom levonorgestrelimpregnated intrauterine system (LNG-IUS) (Mirena, Bayer HealthCare, Berlin, Germany) was inserted.

Patients were followed regularly in the outpatient clinic every 2-4 weeks starting from the time of hyperplasia diagnosis and underwent a second endometrial sampling after 6 months and followed-up for 24 months thereafter to detect relapses. Patients with recurrent bleeding and/or persistent endometrial hyperplasia after 6 months of therapy were managed by total abdominal hysterectomy according to our hospital policy.

\section{Outcome measures}

Regression of endometrial hyperplasia after 6 months of progestin therapy was the primary outcome measure. Secondary outcome measures included the frequency of side effects during treatment, patient acceptability (in terms of compliance with follow-up, overall satisfaction and advisability of the method to other women) and cost of treatment over the six months of therapy.

\section{Statistical analysis}

Statistical analysis was performed using Statistical Package for the Social Sciences Version 16 (IBM Corp., Armonk, NY, USA). Quantitative data are expressed as means and standard deviations. Chi-squared test and t-test were used to compare the two groups as appropriate. $\mathrm{p} \leq 0.05$ was considered to indicate significance and $\mathrm{p} \leq$ 0.001 was considered to indicate strong significance.

\section{Results}

Out of 192 eligible perimenopausal women attending the hospital with AUB, 162 patients fulfilled our inclusion criteria and equally allocated into three groups with 12 patients dropped from the study and 150 patients (50 in each group) completed the study. Figure 1: The flow diagram. Table 1 displays the patients' characteristics. There was no significant difference between the three groups regarding age, parity and body mass index ( $>0.05$ ). Table 2 reveals the outcome and cost of treatment, there was no significant difference between the three groups regarding regression of endometrial hyperplasia ( $88 \%$ in MPA group, $84 \%$ in NETA group and $94 \%$ in LNG-IUS group with p-value $>0.05$ ). There was a highly statistically significant difference between the three groups regarding the cost of treatment over 6 months with the highest cost in LNG-IUS group, p-value $<0.001$.

Table 3 displays the adverse effects of progestin therapy, there was a significant higher women suffering from nausea in NETA group (p-value $<0.05$ ), acne in MPA group ( $\mathrm{p}-$-value $<0.001)$ and vaginal discharge in LNG-IUS group ( $\mathrm{p}$-value $<0.05$ ). Table 4 reveals the patient acceptability, there was a significant higher compliance with follow-up, overall satisfaction and advisability of the method to other women in LNG-IUS group ( $\mathrm{p}$-value $<0.05$ ).

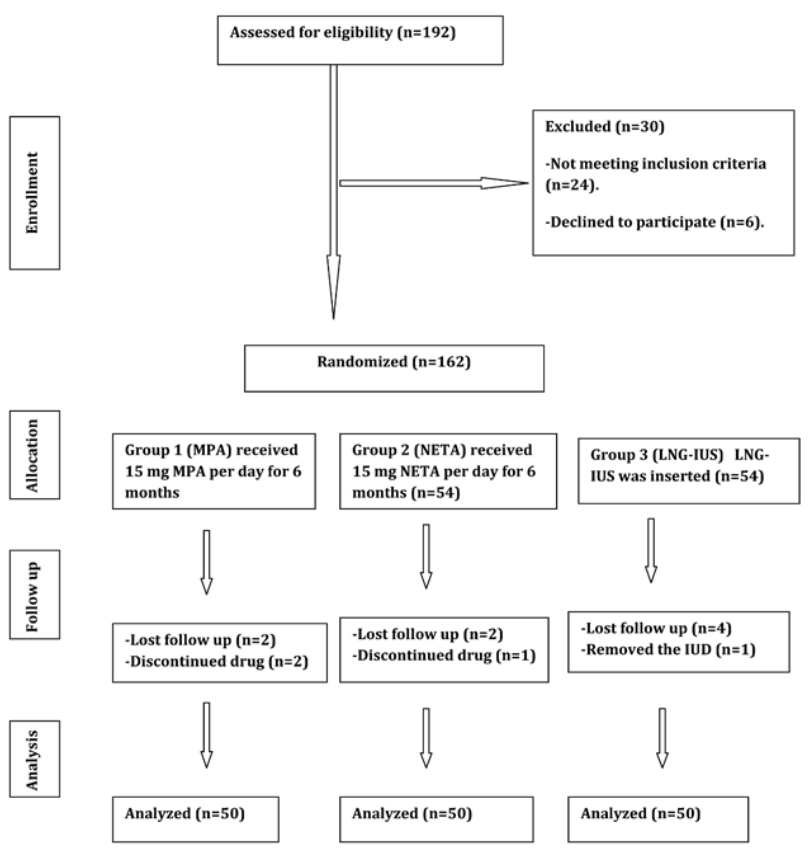

Figure I Flow Diagram.

\section{Discussion}

In our study, there was no significant difference between the three groups regarding regression of endometrial hyperplasia $(\mathrm{EH})$ without atypia (88\% in MPA group, $84 \%$ in NETA group and $94 \%$ in $\mathrm{LNG}^{-}$ IUS group. These results are in agreement with previous studies..$^{7-10}$ In this study, No patients experienced recurrence of genital bleeding during the subsequent 20 months following the second endometrial sampling. Patients with persistent endometrial hyperplasia underwent total abdominal hysterectomy (6 patients in MPA group, 5 patients in NETA group and 6 patients in LNG-IUS group).

Regression of endometrial hyperplasia has been observed in 60 $90 \%$ of subjects receiving cyclic MPA for 3-6 months. ${ }^{7,11}$ Horn et al. ${ }^{8}$ conducted a study in which women with complex EH without atypia were treated with norethindrone acetate ( $5 \mathrm{mg} /$ day) and MPA (10-20 $\mathrm{mg} /$ day) for 3-5 months, and a second biopsy was obtained; regression was evident in $61.5 \%{ }^{8}$ Regression of endometrial hyperplasia was achieved in $94.8 \%$ of patients treated with the LNG-IUS compared with $84.0 \%$ of patients treated with oral progestogens in a recent study with long term follow-up. ${ }^{10}$

In a previous randomized trial, Eighty-two women with simple $\mathrm{EH}$ without atypia were included. Patients were randomized to one of three options for 3 months: medroxyprogesterone acetate (MPA, $10 \mathrm{mg} /$ day), lynestrenol (LYN, $15 \mathrm{mg} /$ day) and norethisterone (NET, $15 \mathrm{mg}$ /day) for 10 days per cycle. No significant difference between progestins regarding the regression rate of EH which was $36.7 \%$ in MPA group, $37 \%$ in LYN group and 56\% in NET group after 3 month treatment. ${ }^{9}$ The lower rate of regression of EH in this study compared to our results may be attributed to lower dose and shorter duration of progestin therapy which were administered for only 10 days per month and for only 3 months. Bese et al. ${ }^{12}$ evaluated the effect of 3 months of cyclic progesterone (NET, $15 \mathrm{mg}$ /day) treatment on proliferation and apoptosis in simple EH without atypia and reported that progesterone treatment reduced both proliferative and apoptotic activities in endometrial tissue of these patients. ${ }^{12}$ 
Table I Patients' Characteristics

\begin{tabular}{llllrr}
\hline & $\begin{array}{l}\text { Group I } \\
\text { (MPA, } \mathbf{n = 5 0 )}\end{array}$ & $\begin{array}{l}\text { Group 2 } \\
\text { (NETA, } \mathbf{n = 5 0 )}\end{array}$ & $\begin{array}{l}\text { Group 3 } \\
(\text { LNG-IUS, n=50) }\end{array}$ & Student t-test & p-value \\
\hline Age & $44.56 \pm 4.07$ & $45.53 \pm 3.89$ & $44.63 \pm 4.19$ & 0.005 & $>0.05$ \\
Parity & $2.5 \pm 0.77$ & $2.4 \pm 0.62$ & $2.06 \pm 0.73$ & $3.01 *$ & $>0.05$ \\
Body mass index & $21 \pm 3.04$ & $22.1 \pm 2.05$ & $21 \pm 4.1$ & 0.28 & $>0.05$ \\
\hline
\end{tabular}

*Wallis Kruskal test.

Table 2 Outcome and cost of treatment

\begin{tabular}{|c|c|c|c|c|}
\hline & $\begin{array}{l}\text { Group I (MPA, n=50) } \\
n(\%)\end{array}$ & $\begin{array}{l}\text { Group } 2 \text { (NETA, n=50) } \\
n(\%)\end{array}$ & $\begin{array}{l}\text { Group } 3 \text { (LNG-IUS, n=50) } \\
n(\%)\end{array}$ & Chi squarep-value \\
\hline $\begin{array}{l}\text { Regression of EH } \\
\text {-Simple EH } \\
\text {-Complex EH }\end{array}$ & $\begin{array}{l}44(88 \%) \\
3014\end{array}$ & $\begin{array}{l}42(84 \%) \\
2913\end{array}$ & $\begin{array}{l}47(94 \%) \\
3215\end{array}$ & $>0.05$ \\
\hline $\begin{array}{l}\text { Cost of treatment in } £ E \\
\text { (US\$) }\end{array}$ & $\begin{array}{l}700 \pm 16.8 £ E \\
(100 \pm 2.4 \text { US\$) }\end{array}$ & $\begin{array}{l}70 \pm 7.7 £ E \\
(10 \pm 1.1 \text { US\$) }\end{array}$ & $\begin{array}{l}700 \pm 326.9 £ E \\
(100 \pm 46.7 \text { US\$) }\end{array}$ & $<0.001$ \\
\hline
\end{tabular}

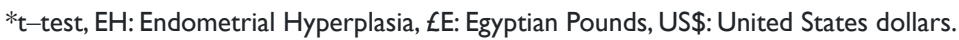

Table 3 Adverse effects of progestin therapy

\begin{tabular}{|c|c|c|c|c|c|}
\hline & $\begin{array}{l}\text { Group I } \\
(M P A, n=50)\end{array}$ & $\begin{array}{l}\text { Group } 2 \\
\text { (NETA, n=50) }\end{array}$ & $\begin{array}{l}\text { Group } 3 \\
\text { (LNG-IUS, n=50) }\end{array}$ & Chi square & p-value \\
\hline Headache & 40 & 23 & 28 & 2.24 & $>0.05$ \\
\hline Nausea & 27 & 43 & 22 & 7.84 & $<0.05$ \\
\hline Weight gain & 24 & 22 & 23 & 0.08 & $>0.05$ \\
\hline Acne & 38 & 18 & 12 & 16.35 & $<0.001$ \\
\hline Menstrual changes & 32 & 29 & 27 & 0.43 & $>0.05$ \\
\hline Mood changes & 21 & 19 & 18 & 0.24 & $>0.05$ \\
\hline Vaginal discharge & 23 & 21 & 40 & 7.78 & $<0.05$ \\
\hline
\end{tabular}

Table 4 Patient acceptability

\begin{tabular}{|c|c|c|c|c|c|}
\hline & $\begin{array}{l}\text { Group I (MPA, } \\
n=50)\end{array}$ & $\begin{array}{l}\text { Group } 2 \\
(\text { NETA, } n=50)\end{array}$ & $\begin{array}{l}\text { Group } 3 \\
(\text { LNG-IUS, n=50) }\end{array}$ & Chi square & P-value \\
\hline \multicolumn{6}{|l|}{ Overall compliance with Follow-up: } \\
\hline -Moderate/High/Extreme & 25 & 27 & 44 & \multirow{2}{*}{6.81} & \multirow{2}{*}{$<0.05$} \\
\hline -None or slight & 25 & 23 & 6 & & \\
\hline \multicolumn{6}{|l|}{ Overall satisfaction with treatment: } \\
\hline -Very or somewhat satisfied & 28 & 30 & 47 & \multirow{2}{*}{6.22} & \multirow{2}{*}{$<0.05$} \\
\hline -Neutral or somewhat not satisfied & 22 & 20 & 3 & & \\
\hline \multirow{2}{*}{$\begin{array}{l}\text { Would recommend the method to other women: } \\
\text {-Highly or somewhat agree } \\
\text {-Neutral or somewhat disagree }\end{array}$} & 24 & 26 & 42 & \multirow{2}{*}{6.34} & \multirow[b]{2}{*}{$<0.05$} \\
\hline & 26 & 24 & 8 & & \\
\hline
\end{tabular}

A recent multicenter randomized trial involving 170 women with low- or medium-risk EH. Eligible women were randomly assigned to one of three treatment arms: levonorgestrel-impregnated intrauterine device (LNG-IUS); oral medroxyprogesterone acetate (MPA) $10 \mathrm{mg}$ administered for 10 days per cycle, or continuous oral MPA $10 \mathrm{mg}$ daily, for 6 months. Regression of EH was obtained for all the women in the LNG-IUS group (100\%), $96 \%$ of women in the continuous oral group and only $69 \%$ of women in the cyclic oral group. ${ }^{13}$

In this study, low-dose progestin therapy for 6 months was chosen as the minimum duration of therapy varies between 8 weeks to 6 months to be followed by a second biopsy ${ }^{14}$ and low dosage seemed more effective when continued for 6 months compared with withdrawal after 3 months. ${ }^{11,13,15}$ In our study, there was a significantly higher women suffering from nausea in NETA group, acne in MPA group and vaginal discharge in LNG-IUS group. Most of these adverse events were reported to be mild-to-moderate in intensity and did not require specific intervention or leaded to discontinuation of therapy.

To the authors' knowledge, this is the first study to assess the cost-effectiveness of progestin therapy because health insurance does not cover the entire population in Egypt as well as in many other low-income countries. NETA was the most cost-effective drug. Although patient acceptability was higher in the LNG-IUS group, it was not cost-effective. A recent systematic review and meta-analysis comparing the LNG-IUS and medical therapy concluded that the LNG-IUS was associated with a lower rate of discontinuation, fewer treatment failures and better quality of life over conventional medical treatment for menorrhagia. ${ }^{16}$

Inability to include women younger than 40 years or postmenopausal women as well as non-using of hysteroscopic guided biopsy, were the main limitations of this study. 


\section{Conclusion}

In conclusion, in low-income and developing countries where the LNG-IUS is unaffordable or unavailable, the use of norethisterone seems a viable cost-effective therapy in patients with endometrial hyperplasia without atypia.

\section{Acknowledgments}

None.

\section{Conflicts of interest}

None.

\section{References}

1. Silverberg SG, Mutter GL, Kurman RJ, et al. Tumors of the uterine corpus: epithelial tumors and related lesions. In: Tavassoli FA \& Stratton MR (Eds.), WHO classification of tumors: pathology and genetics of tumors of the breast and female genital organs. IARC Press, Lyon, France. 2003;pp.221-232.

2. Horn LC, Meinel A, Handzel R, et al. Histopathology of endometrial hyperplasia and endometrial carcinoma: an update. Ann Diagn Pathol. 2007;11(4):297-311.

3. Goncharenko VM, Beniuk VA, Kalenska OV, et al. Predictive diagnosis of endometrial hyperplasia and personalized therapeutic strategy in women of fertile age. EPMA J. 2013;4(1):24.

4. McCausland AM, McCausland VM. Long-term complications of endometrial ablation: cause, diagnosis, treatment, and prevention. $J$ Minim Invasive Gynecol. 2007;14(4):399-406.

5. Nieboer TE, Johnson N, Lethaby A, et al. Surgical approach to hysterectomy for benign gynaecological disease. Cochrane Database Syst Rev. 2009;3:CD003677.

6. Epplein M, Reed SD, Voigt LF, et al. Endometrial hyperplasia risk in relation to recent use of oral contraceptives and hormone therapy. Ann Epidemiol. 2009;19(1):1-7.
7. Wang S, Pudney J, Song J, et al. Mechanisms involved in the evolution of progestin resistance in human endometrial hyperplasia - precursor of endometrial cancer. Gynecol Oncol. 2003;88(2):108-117.

8. Horn LC, Schnurrbusch U, Bilek K, et al. Risk of progression in complex and atypical endometrial hyperplasia: clinicopathologic analysis in cases with and without progestogen treatment. Int J Gynecol Cancer. 2004;14(2):348-353.

9. Ozdegirmenci O, Kayikcioglu F, Bozkurt U, et al. Comparison of the efficacy of three progestins in the treatment of simple endometrial hyperplasia without atypia. Gynecol Obstet Invest. 2011;72(1):10-14.

10. Gallos ID, Krishan P, Shehmar M, et al. LNG-IUS versus oral progestogen treatment for endometrial hyperplasia: a long-term comparative cohort study. Hum Reprod. 2013;28(11):2966-2971.

11. Vereide AB, Arnes M, Straume B, et al. Nuclear morphometric changes and therapy monitoring in patients with endometrial hyperplasia: a study comparing effects of intrauterine levonorgestrel and systemic medroxyprogesterone. Gynecol Oncol. 2003;91(3):526-533.

12. Bese T, Vural A, Ozturk M, et al. The effect of long-term use of progesterone therapy on proliferation and apoptosis in simple endometrial hyperplasia without atypia. Int J Gynecol Cancer. 2006;16(2):809-813.

13. Orbo A, Vereide A, Arnes M, et al. Levonorgestrel-impregnated intrauterine device as treatment for endometrial hyperplasia: a national multicentre randomised trial. BJOG. 2014;121(4):477-486.

14. American College of Obstetricians and Gynecologists. ACOG practice bulletin clinical management guidelines for obstetrician-gynecologists, number 65, August 2005: management of endometrial cancer. Obstet Gynecol. 2005;106(2):413-425.

15. Gunderson CC, Fader AN, Carson KA, et al. Oncologic and reproductive outcomes with progestin therapy in women with endometrial hyperplasia and grade 1 adenocarcinoma: a systematic review. Gynecol Oncol. 2012;125(2):477-482.

16. Qiu J, Cheng J, Wang Q, et al. Levonorgestrel-releasing intrauterine system versus medical therapy for menorrhagia: a systematic review and meta-analysis. Med Sci Monit. 2014;20:1700-1713. 